\title{
Rehydration properties of hybrid method dried fruit enriched by natural components**
}

\author{
Hanna Kowalska ${ }^{1}$, Agata Marzec ${ }^{1}$, Jolanta Kowalska ${ }^{2}$, Agnieszka Ciurzyńska ${ }^{1}$, Kinga Samborska ${ }^{1}$, \\ Michat Bialik ${ }^{1}$, and Andrzej Lenart ${ }^{1}$ \\ ${ }^{1}$ Department of Food Engineering and Process Management, \\ ${ }^{2}$ Department of Biotechnology, Microbiology and Food Evaluation, Division of Food Quality Evaluation; \\ Faculty of Food Sciences, Warsaw University of Life Sciences, Nowoursynowska 159c, 02-776 Warsaw, Poland
}

Received March 23, 2017; accepted December 29, 2017

\begin{abstract}
The aim of the study was to determine the impact of osmotic pre-dehydration and drying of fruit on the rehydration properties of dried fruit. Herein, the effect of fruit juice, applied as a natural enriching substance was very important. In addition, the properties of dried fruits obtained through combined air-drying and subsequent microwave-vacuum drying with 'puffing' effect were similar to the freeze-dried fruits, but showed other rehydration properties. As raw material, frozen strawberry (Honeoye variety) and fresh apples (Idared variety) were used in the study. The apples and partially defrosted strawberries were prior dehydrated in solutions of sucrose and a mixture of sucrose with chokeberry juice concentrate at $50^{\circ} \mathrm{C}$ for $2 \mathrm{~h}$. Next, the fruit samples were dried by one of two ways: air-drying $\left(50^{\circ} \mathrm{C}, 5 \mathrm{~h}\right)$ and microwavevacuum drying for about $360 \mathrm{~s}$; and freeze-drying $\left(30^{\circ} \mathrm{C}, 63 \mathrm{~Pa}\right.$, $24 \mathrm{~h})$. The rehydration was carried out in distilled water $\left(20^{\circ} \mathrm{C}, 5 \mathrm{~h}\right)$. The osmotic pre-dehydration hindered fruit drying process. The impact of drying method became particularly evident while examining the kinetics of rehydration. During the rehydration of the pre-dehydrated dried fruit a slower hydration could be observed. Freeze-dried strawberries absorbed 2-3 times more water than those dried by the 'puffing' effect.

Keywords: apple, strawberry, chokeberry juice, puffing, PCA analysis
\end{abstract}

\section{INTRODUCTION}

An important indicator of quality of dried material is its rehydration capability (Figiel, 2007). The rehydration of plant tissue is directly related to the method used for

*Corresponding author e-mail: hanna_kowalska@sggw.pl **This work was financially supported by SUSFOOD ERA-Net/ NCBiR (National Centre for Research and Development); project No. 5/SH/SUSFOOD1/2014. Implementation period: 2014-2016, Poland. The work was also co-financed by a statutory activity subsidy from the Polish Ministry of Science and Higher Education for the Faculty of Food Sciences of the Warsaw University of Life Sciences. obtaining the dried fruit. This, after the process, does not display the same features as the raw material (Kaleta et al., 2008). The methods of removing water from food result in a variety of changes in the tissue which impairs the possibility for regaining volume, mass and water content. Only freeze-drying allows a water removal at low temperature. It protects the primary structure and the shape of the products, with minimal volume reduction (Ratti, 2001). However, it takes a long time and is not economical. An alternative process is the convection-microwave-vacuum drying technique with 'puffing' effect (hybrid way), which significantly reduces the drying time, and the drought properties are similar to freeze-drying (Figiel, 2010).

Osmotic dehydration promotes a decrease in water content of raw material that makes it a suitable process for the producing of safe products with intermediate water content (Cheng et al., 2014). As holding the potential to obtain better food products by removing water at low temperature, it has been widely used as a pre-treatment step in the food drying process since it can reduce the overall energy requirement for further drying process (Akbarian et al., 2014; Bruijn and Bórquez, 2014; Chandra and Kumari, 2015; Mauro et al., 2016; Nuñez-Mancilla et al., 2013; Yadav and Singh, 2012). Besides the sugar infusion, other natural biocomponents, e.g. those naturally present in a fruit juice concentrate, penetrate the dehydrated fruits. Both the sugar and these substances affect the water activity in the material. However, osmosis often increases the mechanical resistance of the tissue, and therefore, the initial dewatering can positively influence the process of drying and rehydration.

(C) 2018 Institute of Agrophysics, Polish Academy of Sciences 
The aim of the study was to achieve an attractive product through pre-dehydration and simultaneous enrichment of apple and strawberry samples utilising chokeberry concentrate ingredients, and then drying the material by the convection-microwave-vacuum method (a hybrid approach). The properties of the indicated dried product were compared with the osmotic freeze-dried fruit.

\section{MATERIALS AND METHODS}

The research material was constituted of strawberry halves of the Honeoye variety having the diameter of about $3 \mathrm{~cm}$, as well as apples of the Idared variety cut into $15 \times 10$ $\mathrm{mm}$ rings. The fresh strawberries were frozen at the temperature of $-40^{\circ} \mathrm{C}$ for $2 \mathrm{~h}$ and then stored at the temperature of $-20^{\circ} \mathrm{C}$. The apples were stored in a refrigerator at the temperature of approx. $5^{\circ} \mathrm{C}$. The apples and partially defrosted strawberries (for about $15 \mathrm{~min}$ ) were dehydrated in solutions with a concentration of about $60 \%$. Sucrose solution (SA) and a mixture at the ratio of 1:4 of sucrose and chokeberry Aronia melanocarpa juice concentrate (SA-CJC) of about $65^{\circ}$ Brix were used for osmotic pre-treatment. The temperature of the process was $50^{\circ} \mathrm{C}$ and time $2 \mathrm{~h}$. The convection drying was carried out at temperature of $50^{\circ} \mathrm{C}$ for $5 \mathrm{~h}$. In order to obtain the effect of 'puffing', the fruit was dried in the microwave-vacuum drier (MVD) (the hybrid or 'puffing' effect) for about $6 \mathrm{~min}$. Before freeze-drying (F-D), the samples were frozen at $-40^{\circ} \mathrm{C}$ for $2 \mathrm{~h}$ and then dried at the temperature of heating shelves equal to $30^{\circ} \mathrm{C}$ under the pressure of $63 \mathrm{~Pa}$ for $24 \mathrm{~h}$. The rehydration was carried out in distilled water having the temperature of $20^{\circ} \mathrm{C}$ and the range of $0-5 \mathrm{~h}$. A two-factor analysis of variance ANOVA at two levels of volatility and a simple and multiple regression analysis were used for the evaluation of the obtained results (significance level 0.05). Principal component analysis (PCA) was also performed.

\section{RESULTS AND DISCUSSION}

Osmotic dehydration of apples and strawberries in solutions of sucrose and chokeberry juice concentrate (CJC) mixture resulted in a significantly higher (about 7-8\%) mass loss compared to dehydration in sucrose solution without CJC (Table 1). Simultaneously, considerably higher, $19-20 \%$, mass loss of strawberries was noticed in comparison with apples dewatered in the same osmotic solutions. Moreover, the statistical analysis showed the substantial impact of the type of raw material and osmotic substance on water loss and solid gain in the examined fruit. Compared to apples, greater mass loss of dehydrated strawberries results from approximately twice as high water loss. Moreover, smaller solid gain, in particular with the application of the sucrose with chokeberry concentrate solution, was seen. The ratio of water loss to solid gain (WL/SG) in dehydrated strawberries was also much higher, even three times more so, in comparison with the apples. Osmotic dehydration of fruit brought a decrease of moisture content in apples from 86.2 (in fresh) to $71-72 \%$ and from 91.1 (in frozen) to $75-78 \%$ in strawberries. Akbarian et al. (2014) showed that osmo-dehydrated products with removed 30 to $70 \%$ water were ready to use and can be consumed as shake ingredients or snack commodities. The addition of chokeberry concentrate to sucrose solution resulted in a lower moisture content, especially in strawberries. The better dewatering effect and lower solid gain related to fruit might have been the result of the higher molecular weight of the components contained in the solution with chokeberry concentrate addition, which found it more difficult to penetrate into the interior of the dehydrated tissue.

Osmotic pre-concentration is an effective way to reduce water content with minimal damage to fresh product quality (Akbarian et al., 2014). In our work, the drying of fresh fruit resulted in a significantly bigger mass loss (86-90\%)

Table 1. Moisture content $\left(\mathrm{MC}_{\mathrm{OD}}\right)$, mass loss $\left(\mathrm{ML}_{\mathrm{OD}}\right)$, water loss $(\mathrm{WL})$, solids gain $(\mathrm{SG})$ and the ratio of water loss to solid gain (WL/SG) in osmodehydrated apples and strawberries

\begin{tabular}{|c|c|c|c|c|c|}
\hline \multirow{2}{*}{$\begin{array}{l}\text { Kind of osmotic } \\
\text { substance }\end{array}$} & $\mathrm{MC}_{\mathrm{OD}}$ & $\mathrm{ML}_{\mathrm{OD}}$ & WL & SG & \multirow{2}{*}{ WL/SG } \\
\hline & \multicolumn{2}{|c|}{$(\%)$} & \multicolumn{2}{|c|}{ ( $\mathrm{g} \mathrm{g}^{-1}$ i. d.m.) } & \\
\hline \multicolumn{6}{|c|}{ Apple } \\
\hline - & $86.2 \mathrm{~A} \pm 1.7$ & - & - & - & - \\
\hline SA & $72.0 \mathrm{aB} \pm 2.4$ & $22.28 \mathrm{aA} \pm 1.36$ & $2.19 \mathrm{aA} \pm 0.07$ & $0.58 \mathrm{aA} \pm 0.03$ & $3.8 \pm 0.31$ \\
\hline SA-CJC & $71.2 \mathrm{aB} \pm 1.4$ & $30.31 \mathrm{aB} \pm 2.39$ & $2.65 \mathrm{aA} \pm 0.09$ & $0.44 \mathrm{aA} \pm 0.05$ & $6.0 \pm 0.66$ \\
\hline \multicolumn{6}{|c|}{ Strawberries } \\
\hline - & $91.1 \mathrm{~A} \pm 3.6$ & - & - & - & - \\
\hline SA & $78.5 \mathrm{aB} \pm 2.5$ & $41.92 \mathrm{bA} \pm 2.15$ & $4.40 \mathrm{bA} \pm 0.19$ & $0.50 \mathrm{aA} \pm 0.02$ & $10.6 \pm 0.54$ \\
\hline SA-CJC & $74.8 \mathrm{aB} \pm 1.8$ & $49.16 \mathrm{bB} \pm 2.69$ & $5.15 \mathrm{bA} \pm 0.21$ & $0.30 \mathrm{aA} \pm 0.05$ & $18.2 \pm 0.78$ \\
\hline
\end{tabular}

Homogeneous groups: a, b - type of fruit; A, B - type of osmotic substance. 
in comparison with the use of the osmotic pre-treatment (69-88\%) (Table 2). We did not observe any impact of the osmotic solution type in the osmotic pre-treatment on the mass loss of dried fruit. However, in most cases, the use of sucrose with chokeberry concentrate solution resulted in a slightly smaller mass loss than when a sucrose solution without CJC was used. Still, the osmotically pre-dehydrated dried apples were characterised by lower moisture content. In the case of the dried strawberries, the result was converse, but these were not statistically significant differences. We also found that dried fruit obtained by the same method, although, using a variety of osmo-active substances, presented very similar values of moisture content and mass loss. The indicators differed depending on the drying method. Similarly, the study conducted by Changure et al. (2008) revealed that the type of osmotic pre-treatment of strawberries did not affect the hybrid method of convection and vacuum-microwave drying. Simultaneously, it provided the possibility to obtain a higher quality product as far as the effects of rehydration were concerned. In addition, the studies conducted by Kowalski and Mierzwa (2013) showed that the osmotic pre-treatment of apples exerted only a slight effect on the kinetics of convective drying with microwave-vacuum drying. Despite the lower initial water content in osmo-dehydrated samples, the drying time to reach the required water content and water activity was not significantly changed, and in most cases, was increased. With regard to low moisture content, the water activity $\left(a_{w}\right)$ of the dried fruit was widely varied (0.22-0.63), however, this came about at a level which ensured their microbiological stability. In the case of the dried apples, a slightly lower water activity were noted in samples without the osmotic-treatment. The water activity of the freeze-dried fruit was within $0.22-0.26$, whereas that of the dried by the convective drying with the 'puffing' effect was about 0.40 . Therefore, the drying method had a significant effect on the water activity of both dried fruits. Strawberries revealed significantly higher water activity values, especially in the 'puffing' dried fruit (0.40-0.63).

At the beginning of the dried fruit rehydration, up to about $1 \mathrm{~h}$, the mass gain $(\Delta \mathrm{m})$ was the greatest (Fig. 1). The control droughts without pre-treatment showed higher rehydration ability than did the osmo-hybrid dried one. The mass gain kinetics of osmotically dehydrated and freezedried apples rehydration was similar to that of the 'puffing' dried fruit without the osmotic pretreatment. In the case of the dried strawberries, we observed a significant impact of the drying method on the kinetics of rehydration. Freezedried strawberries presented a 2-3 times greater capacity to absorb water when compared with the dried fruit obtained

Table 2. Moisture content (MC), mass loss (ML) and water activity $\left(\mathrm{a}_{\mathrm{w}}\right)$ in dried apples and strawberries

\begin{tabular}{|c|c|c|c|c|}
\hline $\begin{array}{c}\text { Kind of osmotic } \\
\text { substance }\end{array}$ & Drying methods & $\mathrm{MC}(\%)$ & ML (\%) & $\mathrm{a}_{\mathrm{w}}(-)$ \\
\hline \multicolumn{5}{|c|}{ Apple } \\
\hline Raw material & & $5.52 \mathrm{aB} A \pm 0.02$ & $86.23 \mathrm{aB} A \pm 0.65$ & $0.393 \mathrm{aB} A$ \\
\hline SA & C-MVD & $4.37 \mathrm{aB} A \pm 0.11$ & $69.94 \mathrm{aB} A \pm 1.32$ & $0.401 \mathrm{aB} A$ \\
\hline SA-CJC & & $4.73 \mathrm{aB} A \pm 0.21$ & $68.64 \mathrm{aA} \pm 1.46$ & $0.402 \mathrm{aB} A$ \\
\hline Raw material & & $5.49 \mathrm{aA} A \pm 0.16$ & $87.53 \mathrm{aB} A \pm 0.65$ & $0.222 \mathrm{aA} A$ \\
\hline SA & F-D & $3.40 \mathrm{aA} A \pm 0.13$ & $78.25 \mathrm{aB} A \pm 1.32$ & $0.261 \mathrm{aA} A$ \\
\hline SA-CJC & & $2.49 \mathrm{aA} A \pm 0.05$ & $79.91 \mathrm{aB} A \pm 1.18$ & $0.241 \mathrm{aA} A$ \\
\hline \multicolumn{5}{|c|}{ Strawberries } \\
\hline Raw material & & $3.06 \mathrm{aB} A \pm 0.22$ & $89.93 \mathrm{aB} A \pm 0.92$ & $0.631 \mathrm{bB} A$ \\
\hline SA & C-MVD & $4.10 \mathrm{aB} A \pm 0.13$ & $78.59 \mathrm{aB} A \pm 1.54$ & $0.615 \mathrm{bB} A$ \\
\hline SA-CJC & & $6.52 \mathrm{aB} A \pm 0.11$ & $78.14 \mathrm{aB} A \pm 1.17$ & $0.399 \mathrm{bB} A$ \\
\hline Raw material & & $1.05 \mathrm{aA} A \pm 0.13$ & $89.93 \mathrm{aB} A \pm 0.92$ & $0.265 \mathrm{bA} A$ \\
\hline SA & F-D & $1.34 \mathrm{aA} A \pm 0.12$ & $87.74 \mathrm{aB} A \pm 1.54$ & $0.319 \mathrm{bA} A$ \\
\hline SA-CJC & & $1.22 \mathrm{aA} A \pm 0.14$ & $87.27 \mathrm{aB} A \pm 1.43$ & $0.317 \mathrm{bA} A$ \\
\hline
\end{tabular}

C-MVD - convective and microwave-vacuum drying, F-D - freeze-drying. Other explanations as in Table 1. Homogeneous groups: a, b - kind of fruit; A, B - method of drying; $A$ - osmotic substance. 


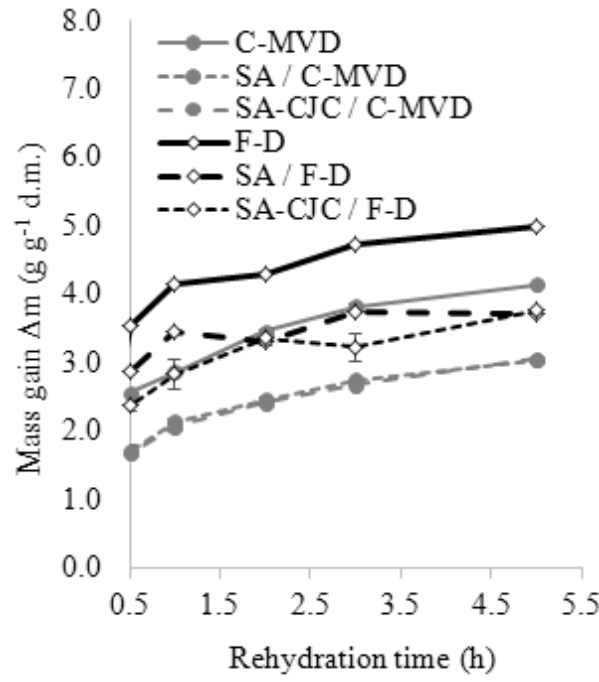

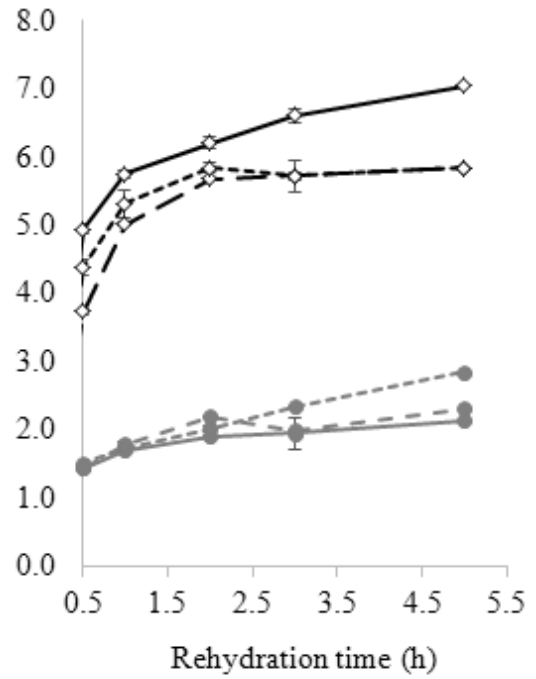

Fig. 1. Kinetics of mass gain during rehydration in dried: $a$ - apples, $b$ - strawberries.

Tab le 3. Multiple regression of rehydration indicators as a function of process parameters

\begin{tabular}{cccccccc}
\hline $\begin{array}{c}\text { Rehydration } \\
\text { indicators }\end{array}$ & Slope & $\begin{array}{c}\text { Drying } \\
\text { methods }\end{array}$ & $\begin{array}{c}\text { Osmotic } \\
\text { substance }\end{array}$ & $\begin{array}{c}\text { Time of } \\
\text { rehydration }\end{array}$ & Kind of fruit & $\begin{array}{c}\text { Regression } \\
\text { coefficient } \mathrm{R}^{2}\end{array}$ & $\begin{array}{c}\mathrm{R}^{2} \\
(\text { corrected })\end{array}$ \\
\hline$\Delta \mathrm{m}$ & 2.048 & 1.897 & -0.387 & 0.203 & 0.765 & 0.630 & $61.7 \%$ \\
$\Delta \mathrm{s}$ & 0.750 & 0.050 & -0.032 & 0.033 & -0.017 & 0.487 & $45.9 \%$ \\
\hline
\end{tabular}

$\Delta \mathrm{m}$ - mass gain, $\Delta \mathrm{s}-$ solid loss.

by the convective and 'puffing' way (the hybrid approach). Statistical analysis indicated significant differences between the mass gain depending on the raw material, type of osmotic substance, the drying method and the time of rehydration. According to the regression equation (Table 3), mass gain resulted mostly from the drying method applied. The type of fruit, osmotic substance (chokeberry concentrate addition) and the time of rehydration less impacted the mass gain of the rehydrated fruit.

Changure et al. (2008) have shown that pre-dehydration hinders the rehydration process because it reduces the number of empty intercellular spaces, and the surface of the cell is coated with an osmo-active substance which creates a barrier to water penetration. Moreover, the method of drying changes the structure of fruit cells, which affects the dynamics and the hydration effect. The method of drying turned out to be dominant and it irreversibly changed the structure of the dried fruit. The indicated effect was even more pronounced in strawberries. A 2-3 times bigger mass gain was noted in freeze-dried fruit when compared with the hybrid (convective and microwave-vacuum) dried one. The said effect was maintained for almost the entire duration of the experiment. In the case of dried strawberry fruit, the differences between the mass gain depending on the type of osmotic substance used in the pre-dehydration were very similar. Slow rehydration is desired when complex mixtures of products with different reconstitution dynamics (such as muesli) are brought together. Therefore, by using an appropriate osmotic substance and drying method, it is possible to obtain a rehydrated product with the desired organoleptic characteristics. Maldonado et al. (2010) revealed that the rehydration kinetics of mango was not affected by osmodehydration pretreatments in sucrose, but the pretreatment in glucose significantly improved rehydration.

During the rehydration (Fig. 2) of dried fruit without osmo-pretreatment, in comparison to with it, solid loss $(\Delta s)$ was slightly higher. However, no big impact of the type of fruit and osmotic substance on the solid loss was observed during the rehydration of dried apples. Still, significant differences were identified in the case of the control test and the fruit dehydrated in a sucrose solution with chokeberry concentrate addition. It was demonstrated that the method of drying and the time of rehydration exert significant effect on solid loss. However, the indicator in dried apples changed to quite a small extent during the whole measurement scope, whereas in the case of freeze-dried strawberries, solid loss was even 2-times higher when compared to rehydration of 'puffed' dried fruit. The regression equation (Table 3 ) indicates that the solid loss was the greatest extent affected by the drying method. The exerted time of rehydration, osmotic substance and type of material held smaller impacts.

Osmotic dehydration as pretreatment can enhance natural flavour and colour, as well as generate softer textures in fruit products (Akbarian et al., 2014). It was noted that the 
a

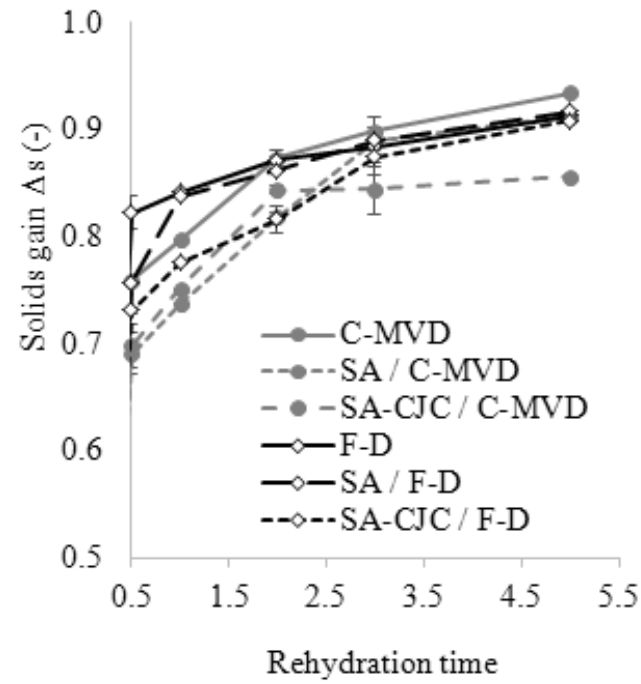

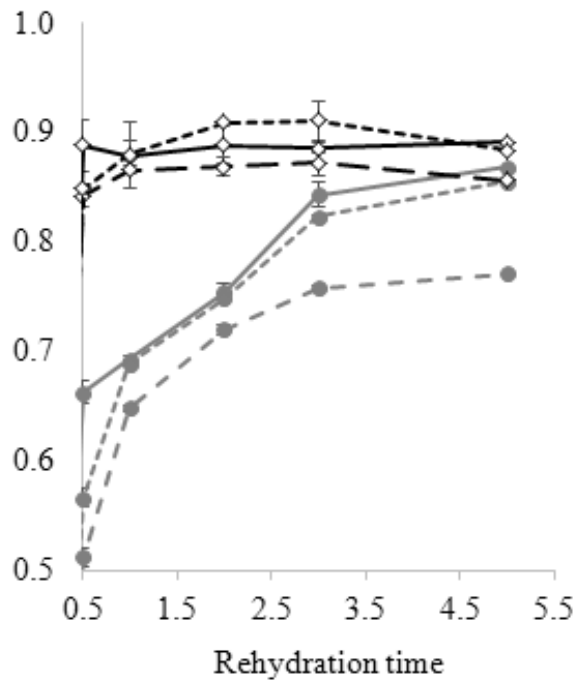

Fig. 2. Kinetics of solid loss during rehydration in dried: $a$ - apples, $b$ - strawberries.

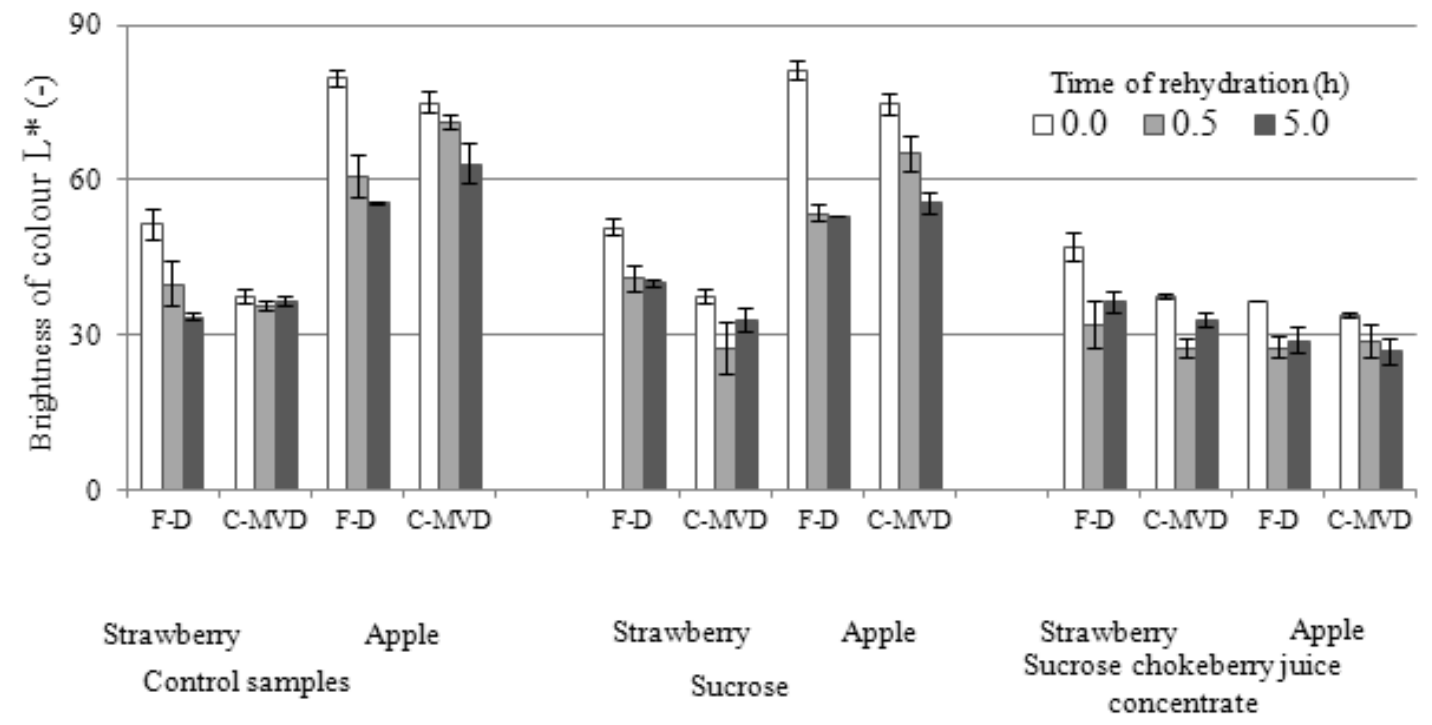

Fig. 3. Effect of osmotic dehydration, drying methods and rehydration on brightness $\mathrm{L}^{*}$ of rehydration dried fruit.

osmotic pre-treatment and drying methods greatly affected the brightness of colour of the dried apples and strawberries before and after rehydration (Fig. 3). Higher values ranging from 71.0 to 81.1 were displayed by the dried apple fruit, particularly the product without the pre-dehydration or the one dehydrated in the sucrose solution. Lower values ranging from 37.4 to 51.5 were observed in control samples of the strawberries dried fruit and the dried fruit dehydrated in the sucrose solution. The lowest brightness was obtained in the dried fruit pre-dehydrated in the sucrose with chokeberry juice concentrate solution (SA-CJC). This was due to the penetration of the chokeberry concentrate ingredients into fruits. Still, in some cases, the dried fruit subjected to a long lasting rehydration turned out to be lighter. This effect is probably associated with the leaching of dyes (osmo-active substance) to water. The rehydration of control samples and dried fruit pre-dehydrated in sucrose solution induced their darkening. The brightness of colour $\mathrm{L}^{*}$ of the dried fruit after rehydration ranged from 52.9 to 71.0 (apple) and from 27.3 to 40.9 (strawberry). As a result of rehydration, the brightness of colour of the dried fruits pre-dehydrated in the sucrose with chokeberry juice concentrate (SA-CJC) solution saw smaller changes, and ranged from 26.7 to 36.2. In addition, we observed that the drying of raw apples by the C-MVD method or dehydrating them in the sucrose solution before drying brought smaller changes in brightness than in the case of the freeze-dried fruits. Rehydration also did not lead to significant degradation of the substance colour (for example, the anthocyanins) in blueberry fruits (Pasławska et al., 2010) and other plant tissue. 


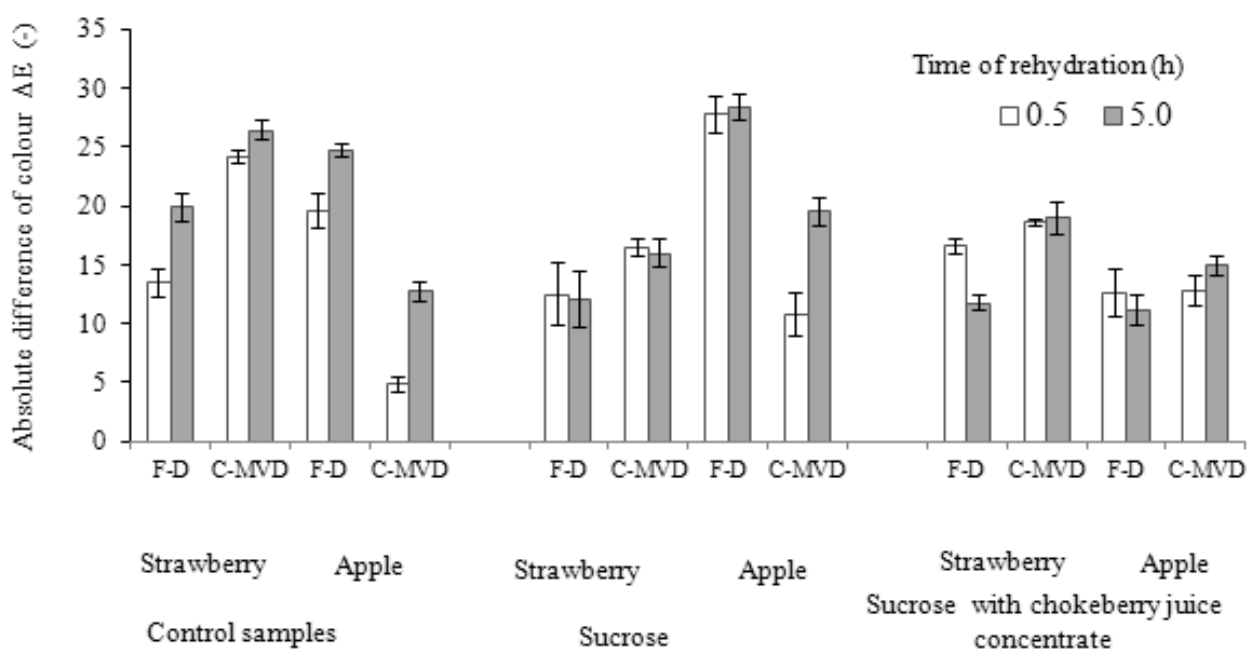

Fig. 4. Effect of osmotic dehydration, drying methods and rehydration on absolute difference of colour DE of rehydration dried fruit.

Rehydration resulted in significant changes of absolute difference of colour $\Delta \mathrm{E}$ of the dried fruits, in comparison with the samples before rehydration (Fig. 4). Due to the specific colour of dried apples, greater changes have occurred in these droughts. The methods of drying and time of rehydration had not a significant effect on the colour change of droughts. We did observe, however, that in the case of the control samples (without prior osmotic dehydration), a longer time rehydration from 0.5 to $5 \mathrm{~h}$ induced a greater change in the colour of the apples and strawberries, but when the samples were osmo-dehydrated in a sucrose solution or in sucrose with chokeberry juice concentrate, the absolute differences of colour varied. Moreover, in most of the samples, preliminary dehydration brought about a reduction in discoloration of drought during rehydration.
In order to find similarities and differences between the analysed types of dried fruits in the aspect of the evaluated osmotic dehydration, drying methods, colour parameters and correlations between them, a principal component analysis (PCA) with classification was conducted, taking into account mean values of individual parameters. By using the sufficient proportion criterion and Kaiser's criterion (Stanisz, 2011), the number of the analysed variables was reduced to two principal components (PC1 and PC2). The selected components PC1 and PC2 explained $72.5 \%$ of the variability of the rehydration properties of dried fruits (Fig. 5a) with simultaneous $27.5 \%$ loss of information. The first component (PC1) included the osmotic dehydration and drying methods parameters, whereas the second principal component (PC2) was constituted by rehydration
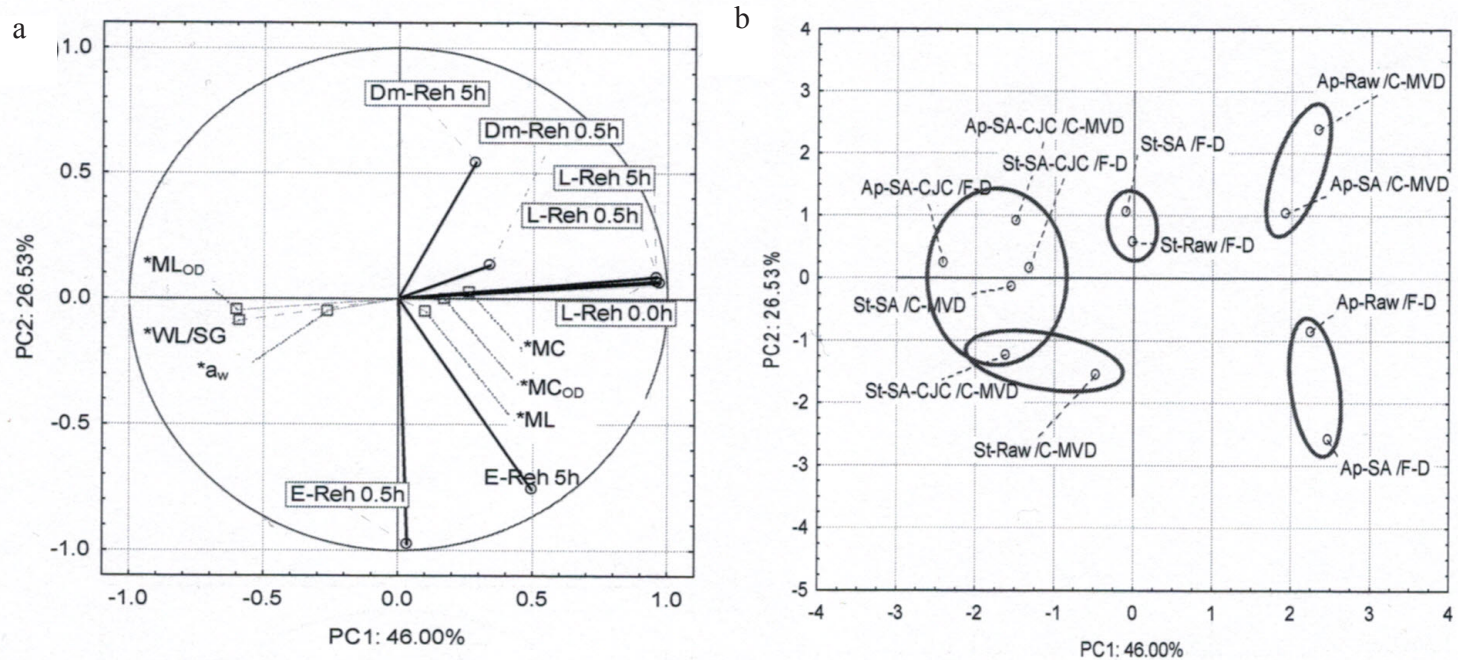

Fig. 5. PCA analysis: a) diagram PCA, b) projection of differences and similarities (Ap - apples, St - strawberries, Raw - no osmotic dehydration droughts, SA - osmotic dehydration in sucrose, SA-CJC - osmotic dehydration in sucrose with cranberry juice concentration, $\mathrm{ML}_{\mathrm{OD}}$ - mass loss during osmotic dehydration, C-MVD - convective-microwave - vacuum drying, F-D - freeze drying, Reh - rehydration, Dm-Reh - mass gain, L-Reh - brightness of colour, E-Reh - absolute difference of colour). 
parameters and colour changes. A greater degree of osmotic dehydration of fruits expressed by mass loss $\left(\mathrm{ML}_{\mathrm{OD}}\right)$, and the ratio of water loss to solids gain (WL/SG) generated less drying effect - expressed by mass loss (ML) and moisture content (MC). These indicators also have influence upon the colour change of the dried fruits during rehydration. Furthermore, they have an effect upon the colour change of the dried fruits during rehydration. The dependence was, however, reversed, i.e. the greater dehydration of fruits resulted in a greater darkening of their colour. While the water activity of fruit droughts were highly correlated with osmotic dehydration parameters, simultaneously, prior osmotic treatment before drying did not affect the absolute difference of colour of the samples after rehydration. The date groups of raw and osmo-dehydrated in sucrose solution of apples and strawberries that were then dried by either of two methods (hybrid and freeze-drying) and subsequently rehydrated were located on two similar parts of the diagram (Fig. 5b). For both dried fruits, the rehydration parameters were similarly dependent upon the osmotic dehydration with added chokeberry juice concentrate, and upon the applied drying method.

\section{CONCLUSIONS}

1. The addition of chokeberry juice concentrate to the sucrose solution had a significant effect on the mass transfer during the osmotic dehydration of apples and strawberries. The chokeberry juice concentrate generated a greater mass loss of fruit by $7-8 \%$, compared to the osmotic solution without it. Furthermore, in strawberries an even 3-times higher effect of dehydration (water loss/solids gain ratio) than that of apples was demonstrated.

2. The application of the type of tissue and osmotic solution, as well as method of drying had a significant influence on the properties of the resulting dried fruit. Convective drying with a 'puffing' effect (the hybrid approach) of osmotically dehydrated apples revealed a significant mass loss (about 70\%), but the loss was slightly smaller than in the case of the freeze-dried fruit (approximately 80\%), while in the case of strawberries, the same figure was, respectively, 80 and $90 \%$.

3. The application of convective drying with a 'puffing' effect after osmotic pre-treatment resulted in the production of dried fruit with similar properties to those obtained by the freeze-drying, which is regarded as a comparative method.

4. The freeze-dried apple rehydration, with regard to mass gain, was slightly higher than in samples dried by convective microwave-vacuum method (the hybrid approach). The freeze-dried strawberries were characterised by a 2-3 times greater capacity to absorb water (higher mass gain), when compared with the dried fruit obtained by the hybrid drying approach (with the 'puffing' effect).
5. In the dried fruit rehydration, the drying method was the most important factor with regard to the ability to absorb water. This effect was most evident in the case of dried strawberry rehydration.

6 . In the tested rehydrates, the addition of the chokeberry juice concentrate into the solution of sucrose resulted in smaller colour changes.

7. For both dried fruits, the rehydration parameters were similarly dependent on the osmotic dehydration with added chokeberry juice concentrate, and on the drying method applied.

Conflict of Interest: The authors declare that they have no conflict of interest.

Compliance with Ethical Requirements: This study does not contain any experiment involving human or animal subjects.

\section{REFERENCES}

Akbarian M., Ghasemkhani N., and Moayedi F., 2014. Osmotic dehydration of fruits in food industrial: A review. Int. J. Biosciences, 4(1), 42-57.

Bruijn J. and Bórquez R., 2014. Quality retention in strawberries dried by emerging dehydration methods. Food Res. Int., 63, 42-48.

Chandra S. and Kumari D., 2015. Recent development in osmotic dehydration of fruit and vegetables: a review. Critical Reviews in Food Sci. Nutrition, 55(4), 552-561.

Changure V., Orsat V., Raghavan G.S.V., 2008. Osmotically dehydrated microvawe vacuum drying of strawberries. J. Food Process. Preserv., 32, 798-816.

Cheng X., Zhang M., Adhikari B., and Islam N., 2014. Effect of power ultrasound and pulsed vacuum treatments on the dehydration kinetics, distribution, and status of water in osmotically dehydrated strawberry: a combined NMR and DSC study. Food Bioprocess Technol., 7(10), 2782-92.

Figiel A., 2007. Dehydration of apples by a combination of convective and vacuum microwave drying. Polish J. Food Nutrition Sci., 57, 131-135.

Figiel A., 2010. Drying kinetics and quality of beetroots dehydrated by combination of convective and vacuum-microwave methods. J. Food Eng., 98, 461-470.

Kaleta A., Górnicki K., Wierzbicka A., and Pacak-Żuk S., 2008. Investigation of the process of rehydration of dried parsley root slices (in Polish). Acta Agrophysica, 12, 689-698.

Kowalski S.J. and Mierzwa D., 2013. Influence of osmotic pretreatment on kinetics of convective drying and quality of apples. Drying Technol., 31, 1849-1855.

Maldonado S., Arnau E., and Bertuzzi M.A., 2010. Effect of temperature and pretreatment on water diffusion during rehydration of dehydrated mangoes. J. Food Eng., 96, 333-341.

Mauro M.A., Dellarosa N., Tylewicz U., Tappi S., Laghi L., Rocculi P., and Dalla Rosa M., 2016. Calcium and ascorbic 
acid affect cellular structure and water mobility in apple tissue during osmotic dehydration in sucrose solutions. Food Chem., 195, 19-28.

Nuñez-Mancilla Y., Pérez-Won M., Uribe E., Vega-Gálvez A., and Di Scala K., 2013. Osmotic dehydration under high hydrostatic pressure: effects on antioxidant activity, total phenolics compounds, vitamin $\mathrm{C}$ and colour of strawberry (Fragaria vesca). LWT-Food Sci. Technol., 52(2), 151-156.

Pasławska M., Stępień B., and Jałoszyński K., 2010. Changes in parameters of berry fruit colour caused by drying, storage and rehydration. Inżynieria Rolnicza, 2(120), 95-103.
Phisut N., 2012. MiniReview. Factors affecting mass transfer during osmotic dehydration of fruits. Int. Food Res. J., 19(1), 7-18.

Ratti C., 2001. Hot air and freeze-drying of high value foods: a review. J. Food Eng., 49, 311-319.

Stanisz A., 2011. The affordable price statistic using STATISTICA PL examples from medicine. 321 Volume 3. Multivariate Analysis. StatSoft. Krakow, Poland.

Yadav A.K. and Singh S.V., 2012. Osmotic dehydration of fruits and vegetables: a review. J. Food Sci. Technol., 51(9), 1654-1673. 